\title{
Proposed concrete compaction method using an electrical internal vibrator: a review of compaction standard for concrete in laboratory according to SNI 2493:2011
}

\author{
Agus Maryoto ${ }^{1, *}$ \\ ${ }^{1}$ Department of Civil Engineering, Engineering Faculty, Jenderal Soedirman University, Indonesia
}

\begin{abstract}
SNI 2493:2011 is the Indonesian National Standard containing the procedures for the manufacture and maintenance of concrete specimens in the laboratory. This standard regulates the way that compaction of compressive specimens is performed using internal vibrators in addition to manual compaction. Unfortunately, the amount and duration of vibrator compaction using an internal vibrator are not specified in the standard. This study examines the effect of vibrator duration when using an internal vibrator to compact concrete compressive strength specimens. The specimens used are of cylinders with diameter $15 \mathrm{~cm}$ and height $30 \mathrm{~cm} .30$ specimens were formed by each of the three concrete compaction methods used. The first type is where concrete is compacted manually by a tamping rod, 25 times each layer. The tamping rod is of $16 \mathrm{~mm}$ diameter and $62 \mathrm{~cm}$ height. The second type is compaction is by using internal vibrator, with 3 compactions per layer, each for 2 seconds. The third type also uses the internal vibrator, except the duration of each compaction is for 5 seconds. The results of compressive strength tests show that the compressive strength of the concrete compacted with the internal vibrator is about $10 \%$ higher than when manually compacting the concrete using a tamping rod. This proposed compaction of concrete by using an internal vibrator can be used as an alternative to manual compaction in the manufacture of concrete compressive strength specimens.
\end{abstract}

\section{Background}

Concrete is used in many civilian buildings, with or without other materials such as wood and steel. Building structures made of concrete have many advantages; high compressive strength, resistance to high temperatures, and flexible design. Concrete materials generally consist of cement, crushed stone, sand, water, and admixture. The key mechanical property of concrete used in structural planning is the compressive strength. The compressive strength of concrete is influenced by many things, including the physical properties of the constituents (i.e. crushed stone, sand, and water), mixing quality, density, curing, capping method, test method, and technician quality.

* Corresponding author: agus_maryoto1971@yahoo.co.id 
The physical properties of crushed stone and sand, which together are the largest constituent by volume in concrete, are the key determinant of concrete quality. A large mud content in crushed stone and sand significantly decreases the compressive strength of the concrete; the presence of mud disrupts the hydration reaction between cement and water. Aggregates are fragile and porous, absorbing water in large quantities. If there is an insufficient amount of water, the hydration reaction cannot complete, thus decreasing the compressive strength of the concrete.

Before compressive testing of concrete is performed, the surface of the test specimen in contact with the Universal Testing Machine should be levelled by using sulphur or rubber capping. The levelling surface of the specimen serves to distribute the load across the surface. If the load is not evenly distributed, the compressive strength of the concrete will decrease, as the force works on a smaller area [1].

Concrete density is influenced by workability and the method used for compaction $[2,3]$. Where concrete has a low slump or dry workability [4], the density is reduced. In addition, many cavities and honeycombs form when it is hard to compact the concrete. The concrete tends to be porous and not a solid material. Concrete aggregates cannot work completely so the compressive strength is reduced. On the other hand, self-compacting concrete typically has a greater compressive strength than conventional concrete $[5,6]$. The degree of compaction significantly affects the compressive strength of the concrete [7].

There are many methods of condensing conventional concrete [8]. In contrast to selfcompacting concrete, which solidifies itself [9], conventional concrete needs special attention during compaction [10]. Some research has been done on the consolidation of concrete on a laboratory scale. One method is to use external compaction or a vibrating table.

As described in Indonesian National Standard SNI 2493:2011 [11], concrete compaction can be done by using a steel bar of diameter $16 \mathrm{~mm}$ and length of $600 \mathrm{~mm}$. For cylindrical objects with diameter of $150 \mathrm{~mm}$ and height of $300 \mathrm{~mm}$, compaction is done in 3 layers, with tamping as much as 25 times each layer. Other compacting methods mentioned in this code allow the use of internal vibrators, but the duration for use of internal vibrators is not clearly mentioned. Based on these conditions, this study was conducted to determine the effect of method and duration of compaction using an internal vibrator to the compressive strength of $20 \mathrm{MPa}$ quality concrete.

\section{Method}

\subsection{Materials and equipment}

The materials used in this study were cement type I, crushed stone, sand, and water. The physical properties of crushed stone and sand were tested for density, specific gravity, mud content, and sieve analysis. The test data were used to create the mix design as listed in Table 1. This research uses equipment such as a concrete mixer, a cylindrical mould of diameter $150 \mathrm{~mm}$ and height $300 \mathrm{~mm}$, a tamping rod, slump apparatus, base plate, an internal electrical vibrator, a rubber hammer, leveller, and thermometer. 
Table 1. Mix proportion of concrete.

\begin{tabular}{|c|c|c|c|}
\hline Component & Weight (kg) & $\begin{array}{c}\text { Concrete } \\
\text { Property }^{\mathbf{1}}\end{array}$ & Specification \\
\hline Cement & 308 & w/c (\%) & 60 \\
\hline Crushed stone & 1061 & s/a (\%) & 43 \\
\hline Sand & 800 & Gmax (mm) & 20 \\
\hline Water & 185 & Slump (cm) & $10 \pm 2$ \\
\hline
\end{tabular}

${ }^{1} \mathrm{w} / \mathrm{c}$ is ratio of water to cement, $\mathrm{s} / \mathrm{a}$ is the ratio of sand to aggregate, and Gmax is the maximum aggregate size.

\subsection{Specimens}

The specimens used were cylinders of diameter $150 \mathrm{~mm}$ and height $300 \mathrm{~mm}$. 30 test specimens were made with each of three types of compaction method as shown in Table 2. The tamping rod used has a diameter of $16 \mathrm{~mm}$ and a length of $600 \mathrm{~mm}$; the internal vibrator (see Figure 1), used for a duration of either 2 or 5 seconds, has a vibrator diameter of $23 \mathrm{~mm}$ and a vibration of $200-258 \mathrm{~Hz}$ or $12,000-15,500 \mathrm{VPM}$ (vibrations per minute). SNI 2493:2011 requires that the vibrator used should vibrate at a minimum of $1600 \mathrm{VPM}$. The vibrator used meets the Indonesian National Standard.

Table 2. Number of specimens and type of compaction.

\begin{tabular}{|c|l|c|c|c|c|}
\hline No & Code $^{\mathbf{1}}$ & $\begin{array}{c}\text { Type of } \\
\text { Compactor }\end{array}$ & $\begin{array}{c}\text { Number of } \\
\text { compaction }\end{array}$ & $\begin{array}{c}\text { Duration of } \\
\text { compaction } \\
\text { (second) }\end{array}$ & $\begin{array}{c}\text { Number of } \\
\text { specimens }\end{array}$ \\
\hline 1 & TR-25 & Tamping rod & 25 & - & 30 \\
\hline 2 & IV-3-2S & Internal vibrator & 3 & 2 & 30 \\
\hline 3 & IV-3-5S & Internal vibrator & 3 & 5 & 30 \\
\hline
\end{tabular}

\footnotetext{
${ }^{1}$ TR means tamping rod, IV represents internal vibrator, and $\mathrm{S}$ is second.
}

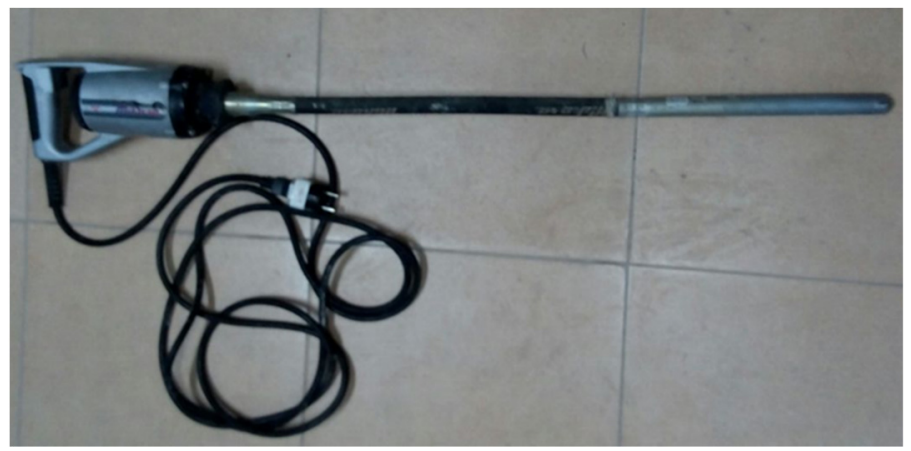

Fig. 1. Internal vibrator. 


\subsection{Procedures of making specimens}

\subsubsection{Mixing of fresh concrete}

Coarse aggregate, fine aggregate, cement, and water were incorporated into the concrete mixer. To ensure even mixing of the concrete material, the concrete mixer was run for 3 minutes. Once the fresh concrete was homogeneously mixed, the mixer was stopped for 3 minutes, then the concrete was mixed for a further 2 minutes. The concrete mixer door was closed throughout mixing to reduce water evaporation [11].

\subsubsection{Slump test}

Slump tests were carried out on the homogenously mixed fresh concrete. The slump cone and base plate were wetted with a wet cloth, and then set in a stable position. The slump cone mould was filled with fresh concrete in 3 layers, each layer filling about one-third of the volume of the slump cone, followed by tamping of each layer as many as 25 times. The surface of the specimen was flattened with the tamping rod and dirt around the slump cone mould was cleaned. The slump cone mould was slowly lifted perpendicularly to the base. For accurate testing, this process - the filling and removal of the mould was completed within 2.5 minutes. The slump that occurs is measured by determining the difference in height between the slump cone and the average height of the specimen [12].

\subsubsection{Compaction}

The fresh concrete was put into cylindrical moulds in 3 layers. Three types of compaction were performed in this study:

1. Each layer is compacted with tamping rod 25 times as shown in Figure 2.

2. Each layer is vibrated with a vibrator at three points for 2 seconds.

3. Each layer is vibrated with a vibrator at three points for 5 seconds.

Compaction with the internal vibrator can be seen in Figure 3. The locations of the three vibration points can be seen in Figure 4. 


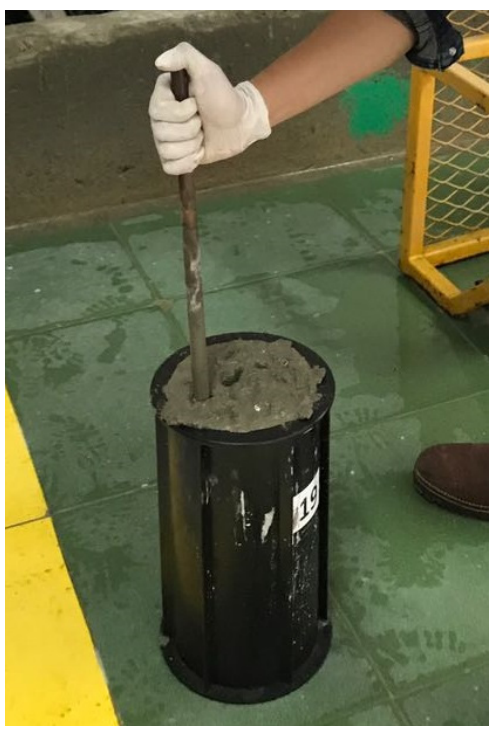

Fig. 2. Compaction using tamping rod.

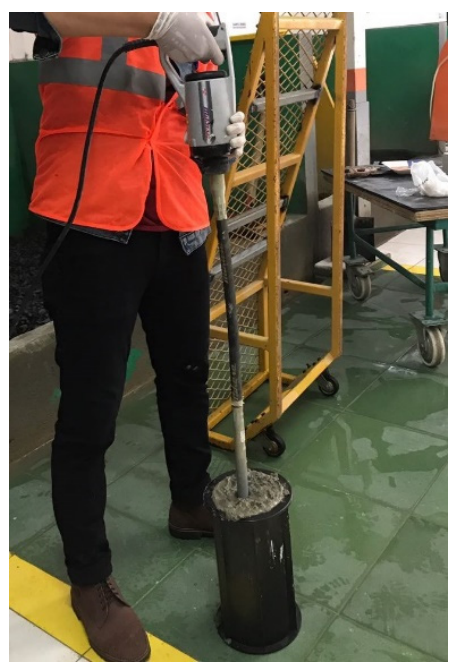

Fig. 3. Compaction using internal vibrator. 


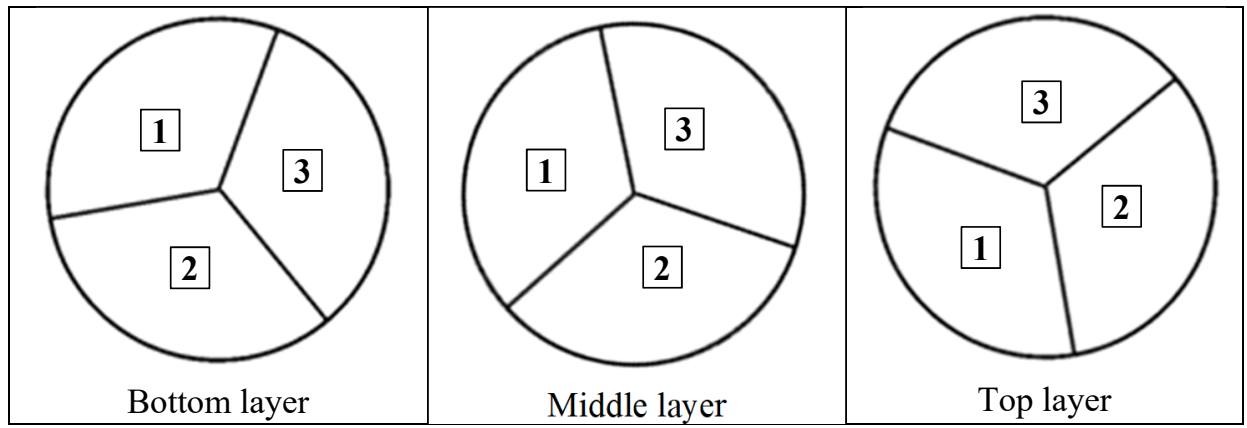

Fig. 4. Position of the 3 compaction points in each layer.

After compaction, the side of the mould was slowly hit with a rubber hammer 10-15 times to close each hole left by the vibrator and to remove the air trapped inside the specimen. The surface of the concrete was flattened with a wooden grinder.

\subsubsection{Curing}

The cylinder formwork was opened $24 \pm 8$ hours after the concrete was cast. The specimens were then soaked in water at a temperature of $23 \pm 1.7^{\circ} \mathrm{C}$. After the specimens had been treated in water for 28 days, the specimens were lifted from the water pond. The surface of the specimens were cleaned of water and dirt, then the top surfaces were coated with capping mortar and the undersides were coated with sulphur capping, according to SNI 03-1974-1990 [13].

\subsection{Compressive strength test}

Compressive strength testing was carried out on the concrete specimens as follows. First, the weight and diameter of each specimen was measured. Then, the specimen was placed centrically on the compression machine (Universal Testing Machine), and the compression machine was run with constant load addition, ranging from 2 to $4 \mathrm{~kg} / \mathrm{cm}^{2}$ per second. The load was increased until the specimen ruptured, and the maximum load that occurred during the examination was recorded. The value of compressive strength can be calculated by Equation 1:

$$
\text { Compressive Strength }\left(f_{c}^{\prime}\right)=\frac{\mathrm{P}}{\mathrm{A}}\left(\mathrm{N} / \mathrm{mm}^{2}\right)
$$

where $\mathrm{P}$ represents the maximum load (Newton), and A is the cross-sectional area $\left(\mathrm{mm}^{2}\right)$.

The compressive strength of the concrete was analysed with a total of 30 test pieces by adopting the 1971 Concrete Rule [14]. The dispersion of test results, or the standard deviation of the compressive strength, can be calculated by Equation 2:

$$
s=\sqrt{\frac{\sum_{1}^{N}\left(\sigma_{b}^{\prime}-\sigma_{b m}^{\prime}\right)^{2}}{N-1}}
$$

where $\mathrm{s}$ is the standard deviation (MPa), $\sigma_{b}^{\prime}$ is the concrete strength of each specimen (MPa), and $\sigma_{b m}^{\prime}$ is the flat concrete strength $(\mathrm{MPa})$. The average concrete compressive strength is calculated according to Equation 3: 


$$
\sigma_{b m}^{\prime}=\frac{\sum_{1}^{N} \sigma_{b}^{\prime}}{N}
$$

where $N$ is the number of specimens tested. Characteristic concrete strength $\left(\sigma_{b k}^{\prime}\right)$ is then determined by Equation 4:

$$
\sigma_{b k}^{\prime}=\sigma_{b m}^{\prime}-1.64 \cdot s
$$

\section{Results and discussions}

\subsection{Temperature and slump}

The temperatures of crushed stone, sand, fresh concrete, water, and the environment are shown in Table 3, along with the result of the slump test, as shown in Figure 5. The temperatures of the crushed stone, sand, and water are in accordance with the requirements specified in SNI 2493:2011; i.e., the temperatures are within the range of $20-30^{\circ} \mathrm{C}$. The temperature of freshly formed concrete is not too hot, although it is higher than the temperature of the raw materials because when cement and water react they release heat through an exothermic reaction. The temperature of fresh concrete greatly affects the compressive strength. The hotter the fresh concrete, the lower the compressive strength, as the water evaporates faster and thus the hydration reaction cannot run perfectly.

Table 3. Temperature of material and slump value.

\begin{tabular}{|c|c|c|c|c|c|}
\hline \multicolumn{5}{|c|}{ Temperature $\left({ }^{\circ} \mathbf{C}\right)$} & Slump \\
Crushed Stone & Sand & Fresh Concrete & Ambient Air & Water & \\
\hline 28 & 25 & 35 & 25 & 24 & $10 \mathrm{~cm}$ \\
\hline
\end{tabular}

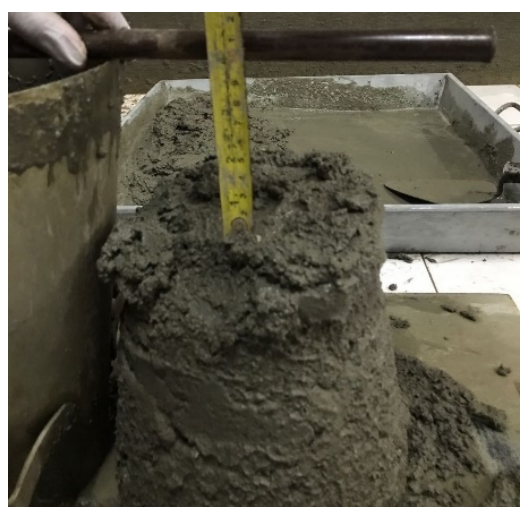

Fig. 5. Slump test.

\subsection{Specimen weight}

The weights of the concrete test specimens are given in Table 4. The lowest average weight was found for the specimens compacted with the tamping rod, at $12.38 \mathrm{~kg}$, while the average weights of those compacted with the internal vibrator were higher; with 2 second vibration, the average weight was $12.41 \mathrm{~kg}$, and with 5 second vibration, the highest average weight was found, at $12.45 \mathrm{~kg}$. 
Table 4. Weight of concrete specimens.

\begin{tabular}{|c|c|c|c|}
\hline \multirow{2}{*}{ No } & \multicolumn{3}{|c|}{ Weight of specimens (kg) } \\
\hline & Code TR-25 & Code IV-3-2S & Code IV-3-5S \\
\hline 1 & 12.44 & 12.40 & 12.49 \\
\hline 2 & 12.41 & 12.40 & 12.48 \\
\hline 3 & 12.41 & 12.40 & 12.47 \\
\hline 4 & 12.40 & 12.39 & 12.49 \\
\hline 5 & 12.44 & 12.39 & 12.47 \\
\hline 6 & 12.41 & 12.46 & 12.46 \\
\hline 7 & 12.44 & 12.47 & 12.47 \\
\hline 8 & 12.36 & 12.48 & 12.48 \\
\hline 9 & 12.41 & 12.47 & 12.47 \\
\hline 10 & 12.44 & 12.49 & 12.49 \\
\hline 11 & 12.36 & 12.39 & 12.43 \\
\hline 12 & 12.35 & 12.37 & 12.43 \\
\hline 13 & 12.35 & 12.39 & 12.45 \\
\hline 14 & 12.38 & 12.41 & 12.44 \\
\hline 15 & 12.36 & 12.42 & 12.45 \\
\hline 16 & 12.41 & 12.43 & 12.35 \\
\hline 17 & 12.38 & 12.44 & 12.37 \\
\hline 18 & 12.38 & 12.47 & 12.40 \\
\hline 19 & 12.38 & 12.46 & 12.42 \\
\hline 20 & 12.41 & 12.47 & 12.40 \\
\hline 21 & 12.36 & 12.35 & 12.49 \\
\hline 22 & 12.37 & 12.24 & 12.47 \\
\hline 23 & 12.37 & 12.37 & 12.46 \\
\hline 24 & 12.35 & 12.37 & 12.47 \\
\hline 25 & 12.39 & 12.41 & 12.45 \\
\hline 26 & 12.38 & 12.37 & 12.44 \\
\hline 27 & 12.32 & 12.39 & 12.46 \\
\hline 28 & 12.36 & 12.35 & 12.48 \\
\hline 29 & 12.35 & 12.38 & 12.46 \\
\hline 30 & 12.37 & 12.32 & 12.45 \\
\hline Average & 12.38 & 12.41 & 12.45 \\
\hline
\end{tabular}

\subsection{Compressive strength of concrete}

The compressive strength results are given in Table 5. The characteristic compressive strength of the test specimen compacted with the tamping rod is $19.83 \mathrm{MPa}$, and those of the specimens compacted with the internal vibrator, for 2 and 5 seconds, are $21.82 \mathrm{MPa}$ and $20.57 \mathrm{MPa}$ respectively. These results indicate that compacting with the internal vibrator increases the characteristic compressive strength compared to with the tamping rod. However, when the vibration time increases from 2 to 5 seconds, the compressive strength of the concrete is reduced, despite the formation of a denser material; the average weight of the concrete specimen compacted with the internal vibrator for 5 seconds is $12.45 \mathrm{~kg}$, while that compacted for 2 seconds is $12.41 \mathrm{~kg}$. This decrease in compressive strength is caused by the segregation that occurs between coarse aggregates and the mortar at longer vibration times. When the concrete composed of crushed stone and mortar during casting is not homogeneous, it will reduce the compressive strength of concrete. 
Table 5. Compressive strength of concrete specimens.

\begin{tabular}{|c|c|c|c|}
\hline No & \multicolumn{3}{|c|}{ Compressive Strength (MPa) } \\
\hline & Code TR-25 & Code IV-3-2S & Code IV-3-5S \\
\hline 1 & 24.3 & 17.5 & 25.3 \\
\hline 2 & 22.9 & 21.2 & 25.9 \\
\hline 3 & 24.4 & 20.1 & 26.2 \\
\hline 4 & 24.7 & 25.9 & 25.6 \\
\hline 5 & 15.4 & 26.2 & 25.4 \\
\hline 6 & 20.3 & 25.5 & 24.2 \\
\hline 7 & 25.6 & 26.6 & 26.0 \\
\hline 8 & 24.3 & 26.8 & 20.8 \\
\hline 9 & 24.1 & 26.7 & 25.5 \\
\hline 10 & 26.4 & 24.8 & 19.8 \\
\hline 11 & 22.1 & 23.6 & 25.2 \\
\hline 12 & 22.8 & 24.1 & 26.0 \\
\hline 13 & 17.6 & 22.8 & 23.8 \\
\hline 14 & 22.4 & 23.2 & 24.4 \\
\hline 15 & 17.4 & 25.4 & 23.9 \\
\hline 16 & 23.2 & 24.2 & 17.5 \\
\hline 17 & 24.4 & 23.1 & 19.4 \\
\hline 18 & 25.8 & 27.3 & 25.5 \\
\hline 19 & 18.5 & 23.9 & 22.1 \\
\hline 20 & 24.4 & 26.7 & 25.4 \\
\hline 21 & 25.2 & 23.3 & 16.1 \\
\hline 22 & 25.3 & 21.0 & 23.0 \\
\hline 23 & 25.2 & 24.5 & 19.5 \\
\hline 24 & 23.8 & 26.3 & 23.5 \\
\hline 25 & 17.9 & 25.3 & 26.2 \\
\hline 26 & 25.9 & 24.8 & 24.0 \\
\hline 27 & 22.0 & 25.3 & 19.7 \\
\hline 28 & 25.4 & 25.3 & 24.5 \\
\hline 29 & 21.2 & 23.7 & 26.1 \\
\hline 30 & 17.9 & 22.8 & 20.1 \\
\hline$\sigma_{b k}^{\prime}{ }^{1}$ & 19.83 & 21.82 & 20.57 \\
\hline $\mathbf{s}^{2}$ & 1.8 & 1.5 & 1.70 \\
\hline
\end{tabular}

${ }^{1} \sigma_{b k}^{\prime}$ is the characteristic concrete strength; ${ }^{2} \mathrm{~s}$ is the standard deviation.

\section{Conclusions}

Based on the above data and discussion, some conclusions can be given as follows:

1. Concrete specimens compacted with the internal vibrator had a greater weight than the concrete specimens compacted with the tamping rod.

2. The compacting method using an internal vibrator for 2 seconds can be used to replace the compacting method using a tamping rod as stated in SNI 2493:2011. It has the highest characteristic concrete strength among 3 compacting concrete method investigated. The characteristic concrete strength is $21.82 \mathrm{MPa}$.

3. Compaction with the internal vibrator for 5 seconds caused segregation and thus decreased the compressive strength of the concrete. The compressive strength is 20.57 $\mathrm{MPa}$.

4. Concrete specimen compacted with the tamping rod has the lowest characteristic strength. The compressive strength of the concrete is $19.83 \mathrm{MPa}$. 
My great appreciation to Mrs. Ir. Ning Nastiti from PT. Holcim Indonesia Cilacap Plant, who provided concrete material and a place to complete this research. Acknowledgments are also conveyed to Muhammad Syarief and the Concrete Laboratory Team at PT. Holcim Indonesia Cilacap Plant, who assisted me in performing this study.

\section{References}

1. D. Vandegrift Jr., A.K. Schindler, High. Res. Cen., (2005)

2. G. Ravi, S.A. Kumar, T.R. Arora, Int. J. Eng. Res. Tech. 2, 8, (2013)

3. M. Tuncan, O. Arioz, K. Ramyar, B. Karasu, A. Tuncan, K. Kilinc, Sir. Bo. Sem. IV, (2007)

4. Sulistyana, Purwanto, V. Widoanindyawati, M.M.A. Pratama, Proc. Eng. 95, (2014)

5. A. Bradu, N. Cazazu, N. Florea, P. Mihai, bul. Inst. Pl. din Iasi. 62, 66, (2016)

6. R. Dubey, P. Kumar, Int. J. Civ. Struc. Env. 2, 3, (2012)

7. T. Gonen, Scie. Tran. 23, 1, (2016)

8. Y. Ardiwinata, J. Tek. Sipil \& Lingk. 3, 1, (2015)

9. S. Juradin, G. Baloevic, A. Harapin, Mat. Res. 17, 1, (2014)

10. T.C. Ling, Cons. Build. Mat. 28, 1, (2012)

11. SNI 2493:2011, BSN, (2011)

12. SNI 03-1972-1990, BSN, (1990)

13. SNI 03-1974-1990, BSN, (1990)

14. PBI 1971 NI-2, DPUTL, (1971) 